\title{
Case-control study of salmeterol and near-fatal attacks of asthma
}

\author{
C Williams, L Crossland, J Finnerty, J Crane, S Holgate, N Pearce, R Beasley
}

\begin{abstract}
Background - A case-control study was undertaken to investigate the hypothesis that the use of the long acting $\beta$ agonist salmeterol increases the risk of a nearfatal attack of asthma.
\end{abstract}

Methods - The cases comprised admissions to the intensive care unit (ICU) for asthma in 14 major hospitals within the Wessex region in 1992. For each of the cases four age-matched controls were selected from asthma admissions to the same hospital during the same period. Information on prescribed drug therapy for the 48 cases and 185 controls was collected from the hospital admission records.

Results - The patients admitted to the ICU had greater chronic asthma severity and had generally been prescribed more asthma drugs than the control admissions to hospital. The relative risk of a near-fatal attack of asthma in patients prescribed inhaled salmeterol was 2.32 (95\% CI 1.05 to 5.16), $\mathrm{p}=\mathbf{0 . 0 4}$. However, the salmeterol relative risk decreased to $1.42(95 \%$ CI 0.49 to 4.10$), p=0.52$ when the analysis was restricted to the more chronically severe patients (those in the subgroup of patients with a hospital admission for asthma in the previous 12 months). These findings suggest that the increased unadjusted relative risk with salmeterol is predominantly due to confounding by severity - that is, the increased relative risk is due to patients with more severe asthma (at greatest risk of a near-fatal asthma attack) being preferentially prescribed salmeterol. This interpretation is supported by the finding in this study that, within the control group (selected from the population of asthmatics requiring hospital admission), salmeterol was preferentially prescribed to the most severe patients (a threefold greater prescription of salmeterol to control patients if they had been admitted to hospital in the 12 months prior to the index admission). There was no increased risk of a near-fatal attack of asthma in patients prescribed a $\beta$ agonist by metered dose inhaler (OR 0.75 (95\% CI 0.31 to 1.78), $p=0.51)$. In contrast, the relative risks for $\beta$ agonists delivered by nebulisation (OR $3.86(95 \%$ CI 1.99 to 7.50$), p<0.001)$ and oral theophylline (OR 2.45 (95\% CI 1.26 to
4.78), $p<0.01$ ) were increased and did not markedly decrease when the analysis was restricted to the more severe asthmatic subjects.

Conclusions - Although these findings are not conclusive, particularly because of the small numbers involved in some subgroup analyses, they suggest that the use of salmeterol by patients with chronic severe asthma is not associated with a significantly increased risk of a near-fatal attack of asthma. If a near-fatal asthma attack is considered to be an intermediate step in a process by which a severe attack of asthma may become fatal, these results would suggest that salmeterol is unlikely to be associated with an increased risk of death, at least by this mechanism.

(Thorax 1998;53:7-13)

Keywords: asthma, mortality, near-fatal attacks, salmeterol, case-control study.

Following the association of the $\beta$ agonists isoprenaline forte and fenoterol with epidemics of asthma mortality ${ }^{1}$ and the detailed investigations of the different acute and long term side effects of $\beta$ agonist drugs, ${ }^{23}$ there has been considerable interest and concern regarding the safety of $\beta$ agonist drug therapy and, in particular, the new generation of long acting $\beta$ agonists such as salmeterol (Serevent). ${ }^{4}$ Clinical studies have convincingly shown a greater duration of bronchodilator action of salmeterol when compared with established agents such as salbutamol ${ }^{5}$ and improved symptomatic control in asthmatic patients with its long term use. ${ }^{6-8}$ Investigations of the long term airways effects of salmeterol have revealed no worsening of bronchial hyperreactivity. ${ }^{9}$ Similarly most, ${ }^{6-10}$ but not all, ${ }^{11}$ studies have found no tolerance to its bronchodilator effects, although a reduction in the protection against bronchoconstrictor stimuli has been observed, ${ }^{9-12}$ the clinical significance of which remains uncertain. By their very nature these long term clinical studies ${ }^{6-1012}$ involving small numbers of asthmatic subjects are unable to determine whether salmeterol may increase the risk of a life threatening or fatal attack of asthma due to the rarity of these adverse events.

In an attempt to investigate specifically whether salmeterol increases the risk of a life threatening or fatal attack of asthma, the Ser- 
event Nationwide Surveillance Project was undertaken. ${ }^{13}$ In this study 25180 asthmatic patients considered to require regular treatment with bronchodilators were randomly allocated to receive either salbutamol $(200 \mu \mathrm{g}$ four times a day) or salmeterol (50 $\mathrm{g}$ twice daily) for a 12 week period with major adverse events recorded to determine whether the regular use of salmeterol led to a worsening of asthma control. The study found that salmeterol did not lead to an increase in the frequency of severe asthma attacks leading to either hospital admission (relative risk $0.95 ; \mathrm{p}=0.7$ ) or withdrawal from the study (relative risk $0.77 ; \mathrm{p}$ $<0.001)$.

However, the study had insufficient power to investigate the relative risk of death associated with salmeterol as there were only 14 deaths in total throughout the study period. As a result, it was not possible to interpret the finding of a "non-statistically significant" ( $p=$ 0.105 ) threefold increased risk of death associated with the prescription of salmeterol. The reassurance offered by the authors that the number of deaths associated with salmeterol was no greater than one would expect in such a group of asthmatic subjects was not entirely convincing and negated the purpose of undertaking a study with an appropriate control group. An alternative interpretation was that it was the inadequate power of the study (and the resulting imprecision in the effect estimates) that prevented the threefold increased risk of death with salmeterol from reaching statistical significance.

Likewise, the results of the subsequent prescription event monitoring study ${ }^{14}$ were inconclusive. In this observational cohort study of over 15000 patients prescribed salmeterol there were 39 deaths due to asthma in patients taking salmeterol in the last month of life. Although the authors concluded that there was no evidence that salmeterol contributed to death in any of the patients examined, no definite clinical criteria were provided (or indeed exist) as to what evidence would indicate such an association, particularly when applied to a group of patients with severe asthma with an increased risk of both morbidity and mortality. As a result of this lack of a control group, matched in terms of chronic asthma severity, the authors were unable to determine whether the use of salmeterol was causally associated with the deaths observed. Likewise, the circumstantial case reports linking patients dying from asthma with salmeterol use are unable to determine whether the drug therapy contributed to the fatal outcome. ${ }^{1516}$

These studies illustrate the difficulties associated with controlled trials, cohort studies, or case reports in the investigation of the role of prescribed drug therapy and asthma mortality. A more appropriate epidemiological approach is to utilise case-control methodology ${ }^{17}$ in which all subjects with the rare adverse event are studied, together with a small but representative proportion of the controls with severe asthma in whom this outcome has not occurred.
There are two outcomes which can be used to select the cases in such a case-control study: death from asthma or a near-fatal attack of asthma. While a fatal attack of asthma is the preferred outcome to study, near-fatal attacks are also worthy of study since any drug which increases the risk of death might also be expected to increase the risk of a near-fatal attack of asthma. Thus, the occurrence of a near-fatal attack of asthma may be an intermediate stage of a process by which a fatal attack of asthma may eventually occur. Although it is necessary to be cautious in interpreting the findings of such studies, ${ }^{18}$ the use of this surrogate case group nevertheless has several practical advantages - life threatening attacks of asthma occur more frequently than asthma deaths, it allows simple identification of the cases through ready access to the medical records of patients admitted to the intensive care unit, and ensures that there is accurate and comparable documentation of regular prescribed drug therapy in both the cases and controls.

In this paper we report the results of a casecontrol study of salmeterol and the risk of a near-fatal attack of asthma.

\section{Methods}

The regular prescribed drug therapy of asthmatic patients admitted to an intensive care unit (ICU) with a near-fatal attack of asthma (cases) was compared with that of asthmatic patients requiring admission to hospital (but not ICU) with severe asthma (controls). Attention focused on the 5-45 year age group because asthma is a reasonably clearcut diagnosis in this age group. ${ }^{19}$ The study was undertaken in the 14 major hospitals within the Wessex Regional Health Authority region.

\section{SELECTION OF CASES}

The eligible cases comprised all persons aged 5-45 years who were admitted to the ICU in the major hospitals of the Wessex Regional Health Authority during the period 1 January 1992 to 31 December 1992. The potential cases were identified from the ICU admission books as having a primary diagnosis of asthma as the cause of admission.

\section{SELECTION OF CONTROLS}

For each case, four controls were selected at random from hospital records of patients discharged from the same hospital with a diagnosis of asthma within the same month in which the case was admitted. The controls were matched by hospital and age (within five years). If sufficient controls could not be obtained, the acceptable admission period was widened to six months and the acceptable age range was widened to 10 years.

INFORMATION ON ACUTE ASTHMA SEVERITY

For both cases and controls, information was recorded as to whether the patient was admitted to an intensive care unit, was mechanically 
ventilated, and the worst arterial carbon dioxide $\left(\mathrm{PaCO}_{2}\right)$ measurement during the admission. Other markers of acute asthma severity such as admission peak flow, arterial oxygen measurements, or clinical examination findings were not utilised as they were not recorded in a standardised manner and/or their interpretation was confounded by other factors such as level of oxygen therapy received.

INFORMATION ON PRESCRIBED DRUG THERAPY For all cases and controls, hospital records were used as the information source for the prescribed drug therapy at the time of admission. Information was recorded from the case notes, general practitioner letter, Accident and Emergency notes, and other sources. It was not possible to perform the data extraction "blind", but all the drug information was recorded from these sources. When more than one record was available from a particular source - for example, in the case notes - then the composite of all the data was used. The data forms were copied and all information that identified cases and controls was deleted. Two different members of the study team then made a blind assessment of the drugs on admission. For oral corticosteroids information in the patient records was used to determine whether they were for long term (continuous) or short term use (associated with the index attack). If it was not clear from the histories, then the oral corticosteroid use was designated "don't know". Previous validation exercises have shown that there is very close agreement between information on drug treatment recorded in hospital records (using the same procedure as that followed in the current study) and that obtained from the patient's general practitioner, and that there are no systematic differences in documentation of $\beta$ agonist therapy between the two sources. ${ }^{20}$

INFORMATION ON CHRONIC ASTHMA SEVERITY The possibility of confounding or effect modification by severity was assessed by considering various subgroups defined by three markers of chronic asthma severity: (1) three or more prescribed categories of asthma drugs at the time of admission (oral or aerosolised $\beta$ agonists, nebulised $\beta$ agonists, theophyllines, sodium cromoglycate or inhaled corticosteroids, and oral corticosteroids); (2) a hospital admission for asthma during the previous 12 months (prior to the index admission under consideration); and (3) prescribed oral corticosteroids at the time of admission. These markers have been shown to identify patients with severe asthma at increased risk of hospital admission or death from asthma. ${ }^{2122}$

DATA ANALYSIS

Data for both cases and controls were entered onto an IBM-compatible microcomputer and analysed using the SAS statistical package. Matched analyses and unmatched analyses were found to give virtually identical results for salmeterol and for other key analyses. For simplicity, unmatched analyses are therefore presented throughout. The Mantel Haenszel ${ }^{23}$ procedure was used to calculated odds ratios (ORs) and test-based confidence intervals (CIs). ${ }^{24}$ The possibility of confounding or effect modification by severity was assessed by calculation of odds ratios in the various subgroups defined by markers of chronic asthma severity. ${ }^{25}$ To determine whether salmeterol was preferentially prescribed to the more severe asthmatic patient, the proportion of control patients prescribed salmeterol in each of the subgroups defined by markers of chronic asthma severity was compared with the proportion not prescribed salmeterol.

\section{Results}

Between 1 January and 31 December 1992 case records of 48 patients (32\% men, mean age 25.5 years) admitted to an ICU in one of the 14 major hospitals in the Wessex region with a near-fatal attack of asthma were identified. For 17 (35\%) of the 48 cases, the hospital records documented that they had been ventilated. The mean (range) worst $\mathrm{PaCO}_{2}$ was 7.3 $(2.4-16.6) \mathrm{kPa}$ in the 45 cases in whom arterial blood gas measurements were recorded. In 25 $(55 \%)$ of these cases the $\mathrm{PaCO}_{2}$ was $>6.0 \mathrm{kPa}$. When the analysis was restricted to the 30 cases with documented mechanical ventilation or worst $\mathrm{PaCO}_{2}>6.0 \mathrm{kPa}$ there was little change in the study findings; thus all 48 cases were included in the analyses.

There were 192 controls (37\% men, mean age 25.4 years) matched on hospital, date of admission, and age. Arterial blood gas measurements were undertaken in 102 of the controls and the mean (range) worst $\mathrm{PaCO}_{2}$ was $4.7(1.6-12.9) \mathrm{kPa}$. The seven controls in whom the $\mathrm{PaCO}_{2}$ was $>6.0 \mathrm{kPa}$ were excluded from subsequent analysis as it was considered that they could have been experiencing a nearfatal asthma attack even though the attending physicians did not arrange for admission to an ICU.

Table 1 shows the relative risks of a nearfatal attack of asthma associated with prescribed drug therapy at the time of admission. There was no increased risk of a near-fatal attack in patients prescribed a $\beta$ agonist by metered dose inhaler (MDI). The relative risk of a near-fatal attack in patients prescribed salmeterol (compared with patients not prescribed salmeterol) was 2.32 (95\% CI 1.05 to 5.16). There was no increased risk associated with salbutamol or terbutaline by MDI.

There were large differences between cases and controls for most other forms of bronchodilator therapy. For example, the relative risk for the prescription of regular nebulised $\beta$ agonist therapy was 3.86 (95\% CI 1.99 to 7.50$)$. The relative risk associated with the prescription of oral theophyllines was increased (odds ratio $2.45 ; 95 \%$ CI 1.26 to 4.78 ), and there was also an increased relative risk of a near-fatal attack amongst patients prescribed antimuscarinic bronchodilators by both MDI and nebuliser. 
Table 1 Prescribed drug therapy, markers of chronic asthma severity, and the relative risk of a near-fatal attack of asthma

\begin{tabular}{|c|c|c|c|c|c|c|c|}
\hline \multirow[t]{2}{*}{ Exposure } & \multicolumn{2}{|c|}{ Cases } & \multicolumn{2}{|c|}{ Controls } & \multirow{2}{*}{$\begin{array}{l}\text { Odds } \\
\text { ratio }\end{array}$} & \multirow[t]{2}{*}{$95 \% C I$} & \multirow[t]{2}{*}{$p$ value } \\
\hline & Yes & No & Yes & No & & & \\
\hline \multicolumn{8}{|l|}{ Drug therapy } \\
\hline$\beta$ agonist MDI & 40 & 8 & 161 & 24 & 0.75 & 0.31 to 1.78 & 0.51 \\
\hline Salbutamol & 36 & 12 & 149 & 36 & 0.73 & 0.34 to 1.53 & 0.40 \\
\hline Fenoterol & 1 & 47 & 1 & 184 & 3.92 & 0.29 to 52.52 & 0.30 \\
\hline Salmeterol & 11 & 37 & 21 & 164 & 2.32 & 1.05 to 5.16 & 0.04 \\
\hline Terbutaline & 2 & 46 & 9 & 176 & 0.85 & 0.18 to 4.08 & 0.84 \\
\hline$\beta$ agonist nebuliser & 21 & 27 & 31 & 154 & 3.86 & 1.99 to 7.50 & $<0.001$ \\
\hline Salbutamol & 19 & 29 & 31 & 154 & 3.26 & 1.66 to 6.39 & $<0.01$ \\
\hline Terbutaline & 2 & 46 & 0 & 185 & - & - & $<0.01$ \\
\hline Oral theophylline & 19 & 29 & 39 & 146 & 2.45 & 1.26 to 4.78 & $<0.01$ \\
\hline Sodium cromoglycate & 4 & 44 & 8 & 177 & 2.01 & 0.59 to 6.85 & 0.26 \\
\hline Inhaled corticosteroids & 35 & 13 & 123 & 62 & 1.36 & 0.67 to 2.75 & 0.40 \\
\hline Oral corticosteroids & 25 & 23 & 77 & 108 & 1.53 & 0.81 to 2.88 & 0.19 \\
\hline Continuous steroids & 11 & 37 & 15 & 170 & 3.37 & 1.48 to 7.66 & $<0.01$ \\
\hline \multicolumn{8}{|l|}{ Antimuscarinic MDI } \\
\hline Atrovent & 5 & 43 & 9 & 176 & 2.27 & 0.74 to 6.96 & 0.15 \\
\hline Oxivent & 3 & 45 & 3 & 182 & 4.04 & 0.88 to 18.52 & 0.07 \\
\hline Atrovent nebuliser & 9 & 39 & 8 & 177 & 5.11 & 2.00 to 13.01 & $<0.01$ \\
\hline Methothrexate & 1 & 47 & 2 & 183 & 1.95 & 0.18 to 21.12 & 0.58 \\
\hline Psychotropics & 5 & 43 & 6 & 179 & 3.47 & 1.08 to 11.18 & 0.04 \\
\hline \multicolumn{8}{|l|}{ Marker of chronic asthma severity } \\
\hline Three or more asthma drugs & 29 & 19 & 77 & 108 & 2.14 & 1.13 to 4.07 & 0.02 \\
\hline Previous admission & 28 & 20 & 50 & 135 & 3.78 & 2.00 to 7.15 & $<0.001$ \\
\hline
\end{tabular}

Table 2 Prescribed salmeterol by MDI and relative risk of a near-fatal attack of asthma: findings in subgroups defined by markers of chronic asthma severity

\begin{tabular}{|c|c|c|c|c|c|c|c|}
\hline \multirow[t]{2}{*}{ Subgroup } & \multicolumn{2}{|c|}{ Cases } & \multicolumn{2}{|c|}{ Controls } & \multirow{2}{*}{$\begin{array}{l}\text { Odds } \\
\text { ratio }\end{array}$} & \multirow[t]{2}{*}{$95 \% C I$} & \multirow[t]{2}{*}{$p$ value } \\
\hline & Yes & No & Yes & No & & & \\
\hline \multicolumn{8}{|c|}{$>3$ asthma drugs } \\
\hline Yes & 10 & 19 & 16 & 61 & 2.01 & 0.79 to 5.13 & 0.15 \\
\hline No & 1 & 18 & 5 & 103 & 1.14 & 0.13 to 10.45 & 0.91 \\
\hline \multicolumn{8}{|c|}{ Previous hospital admission } \\
\hline Yes & 8 & 20 & 11 & 39 & 1.42 & 0.49 to 4.10 & 0.52 \\
\hline No & 3 & 17 & 10 & 125 & 2.21 & 0.57 to 8.60 & 0.25 \\
\hline \multicolumn{8}{|c|}{ Continuous oral steroids } \\
\hline Yes & 4 & 7 & 3 & 12 & 2.29 & 0.39 to 13.53 & 0.36 \\
\hline No & 7 & 30 & 18 & 152 & 1.97 & 0.77 to 5.07 & 0.16 \\
\hline \multicolumn{8}{|c|}{ Continuous oral steroids and previous admission } \\
\hline Yes & 4 & 7 & 3 & 9 & 1.71 & 0.28 to 10.64 & 0.56 \\
\hline No & 7 & 30 & 18 & 155 & 2.01 & 0.78 to 5.17 & 0.15 \\
\hline
\end{tabular}

In contrast, there was less evidence of differences between cases and controls for inhaled and oral anti-inflammatory therapy, with the relative risk for sodium cromoglycate, oral and inhaled corticosteroids being $2.01,1.53$ and 1.36 , respectively. However, when oral corticosteroid use was classified according to continuous use, the relative risk increased to 3.37 (95\% CI 1.48 to 7.66$)$.

Comparison of the markers of chronic asthma severity in cases and controls showed that cases had greater baseline asthma severity than controls (table 1). There were 29 (60\%) cases prescribed three or more asthma drugs compared with $77(42 \%)$ controls (odds ratio $2.14,95 \%$ CI 1.13 to 4.07$)$ and 28 (58\%) cases compared with $50(27 \%)$ controls had a hospital admission for asthma during the previous year (odds ratio 3.78, 95\% CI 2.00 to 7.15 ). The cases had also been prescribed psychotropic drugs more frequently (odds ratio $3.47,95 \%$ CI 1.08 to 11.18 ), indicating greater psychosocial problems.

To investigate whether the increased relative risk associated with different forms of prescribed drug therapy may be confounded by asthma severity - that is, whether the increased risk was due to patients with more severe asthma (at greater risk of a near-fatal attack) being preferentially prescribed a specific drug - the relative risk of a near-fatal attack was calculated in asthma subgroups defined by markers of severity (table 2). For salmeterol the relative risk did not decrease markedly when the analysis was restricted to patients with three or more asthma drugs (OR 2.01, 95\% CI 0.79 to 5.13$)$. However, the odds ratio decreased to 1.42 (95\% CI 0.49 to 4.10$)$ when the analysis was restricted to patients with a hospital admission for asthma during the previous year; this is known to be the most valid available marker of chronic asthma severity. ${ }^{2021}$ In patients with the most severe chronic asthma - that is, those who had been admitted to hospital during the previous 12 months and were prescribed continuous oral corticosteroids - the salmeterol relative risk was 1.71 (95\% CI 0.28 to 10.64$)$.

To assess whether salmeterol was preferentially prescribed to the more severe asthmatic subjects an analysis was undertaken in which the proportion of controls in each severity subgroup that was prescribed salmeterol was calculated (table 3). For controls with a hospital admission during the previous year, 11 out of $50(22 \%)$ were prescribed salmeterol, which contrasts with the 10 out of 135 controls who had not had an admission in the previous 
Table 3 Proportion of controls* prescribed salmeterol: findings in subgroups defined by markers of chronic asthma severity

\begin{tabular}{|c|c|c|c|c|}
\hline \multirow[t]{2}{*}{ Subgroup } & \multicolumn{4}{|c|}{ Prescribed salmeterol } \\
\hline & Yes & $(\%)$ & No & $(\%)$ \\
\hline \multicolumn{5}{|c|}{$>3$ asthma drugs } \\
\hline Yes & 16 & $(21 \%)$ & 61 & $(79 \%)$ \\
\hline No & 5 & $(5 \%)$ & 103 & $(95 \%)$ \\
\hline \multicolumn{5}{|c|}{ Previous hospital admission } \\
\hline Yes & 11 & $(22 \%)$ & 39 & $(78 \%)$ \\
\hline No & 10 & $(7 \%)$ & 125 & $(93 \%)$ \\
\hline \multicolumn{5}{|c|}{ Continuous oral steroids } \\
\hline Yes & 3 & $(20 \%)$ & 12 & $(80 \%)$ \\
\hline No & 18 & $(11 \%)$ & 152 & $(89 \%)$ \\
\hline \multicolumn{5}{|c|}{ Continuous oral steroids and previous admission } \\
\hline Yes & 3 & $(25 \%)$ & 9 & $(75 \%)$ \\
\hline No & 18 & $(10 \%)$ & 155 & $(90 \%)$ \\
\hline
\end{tabular}

* Control group selected from hospital admissions for asthma.

year $(7 \%)$; thus, salmeterol was prescribed about three times more frequently to the more severe patients (defined by a recent hospital admission) than to those with less severe asthma. A similar pattern was observed with the other subgroups of chronic asthma severity - for example, $20 \%$ of controls on continuous oral corticosteroids were prescribed salmeterol compared with $11 \%$ of controls not prescribed continuous oral corticosteroids.

The relative risks for $\beta$ agonists by nebulisation and oral theophylline remained unchanged or increased when subgroups were defined by markers of severity (table 4 ). For nebulised $\beta$ agonist therapy the relative risk rose to 6.38 (95\% CI 2.34 to 17.36 ) in patients with a hospital admission during the previous year; for oral theophylline the risk was 2.33 ( $95 \%$ CI 0.90 to 6.05$)$ in this subgroup. In contrast, the relative risks for inhaled and continuous oral corticosteroids (but not all oral corticosteroids) decreased markedly when the findings were adjusted for severity in this way. For inhaled corticosteroids the relative risk fell to 0.48 (95\% CI 0.16 to 1.44 ).

\section{Discussion}

The findings of this case-control study provide little support for the hypothesis that the use of salmeterol increases the risk of a life threatening attack of asthma. However, these results should be interpreted with caution and, in particular, two major issues need to be addressed - namely, the selection of cases and confounding by severity.

Asthmatic patients who were admitted to an intensive care unit were selected to identify a group of asthmatic subjects who were experiencing a life threatening attack of asthma. The selection criteria were based on clinical studies reporting that patients admitted to an intensive care unit with severe asthma, particularly those with documented respiratory failure or requiring mechanical ventilation, are at considerable risk of a fatal outcome during that episode. ${ }^{26}$ One of the underlying premises of this study was that any drug which increases the risk of death might also be expected to increase the risk of a near-fatal attack. Support for this view comes from the previous casecontrol studies of similar design in which the same pattern and degree of risk associated with prescribed fenoterol were noted when a nearfatal attack or death from asthma were used as the primary outcome measure..$^{2027-30}$ On the other hand, this study is not relevant to possible mechanisms of death that do not involve an increased frequency of near-fatal attacks.

The problem of confounding by severity needs to be considered due to the significant differences in the severity of chronic asthma noted between the cases and controls. Similar differences were observed in a previous casecontrol study of identical design ${ }^{27}$ in which ICU admission with asthma was used as the outcome under study. In both studies the cases who were admitted to the ICU had more severe chronic asthma than an otherwise matched control group who were admitted to hospital with asthma but did not require admission to the ICU. Thus, asthmatic patients requiring ICU admission appear to represent a very severe and problematic group of patients who are likely to be on more drugs, have more frequent hospital admissions, and greater psychosocial problems than those who require uncomplicated hospital admission. ${ }^{18}$

To determine whether the increased overall odds ratio associated with salmeterol and most

Table 4 Prescribed drug therapy and relative risk of near-fatal attack of asthma: findings in cases and controls with a hospital admission with asthma in previous 12 months

\begin{tabular}{|c|c|c|c|c|c|c|c|}
\hline \multirow[t]{2}{*}{ Exposure } & \multicolumn{2}{|c|}{ Cases } & \multicolumn{2}{|c|}{ Controls } & \multirow{2}{*}{$\begin{array}{l}\text { Odds } \\
\text { ratio }\end{array}$} & \multirow[t]{2}{*}{$95 \% C I$} & \multirow[t]{2}{*}{$p$ value } \\
\hline & Yes & No & Yes & No & & & \\
\hline$\beta$ agonist $\mathrm{MDI}$ & 23 & 5 & 43 & 7 & 0.75 & 0.21 to 2.64 & 0.65 \\
\hline Salbutamol & 20 & 8 & 40 & 10 & 0.63 & 0.21 to 1.83 & 0.39 \\
\hline Fenoterol & 1 & 27 & 0 & 50 & - & - & 0.18 \\
\hline Salmeterol & 8 & 20 & 11 & 39 & 1.42 & 0.49 to 4.10 & 0.52 \\
\hline Terbutaline & 1 & 27 & 2 & 48 & 0.89 & 0.08 to 10.41 & 0.93 \\
\hline$\beta$ agonist nebuliser & 21 & 7 & 16 & 34 & 6.38 & 2.34 to 17.36 & $<0.001$ \\
\hline Salbutamol & 19 & 9 & 16 & 34 & 4.49 & 1.70 to 11.83 & $<0.01$ \\
\hline Terbutaline & 2 & 26 & 0 & 50 & - & - & 0.06 \\
\hline Oral theophyllines & 14 & 14 & 15 & 35 & 2.33 & 0.90 to 6.05 & 0.08 \\
\hline Sodium cromoglycate & 3 & 25 & 0 & 50 & - & - & 0.02 \\
\hline Inhaled corticosteroids & 20 & 8 & 42 & 8 & 0.48 & 0.16 to 1.44 & 0.19 \\
\hline Oral corticosteroids & 20 & 8 & 27 & 23 & 2.13 & 0.79 to 5.72 & 0.13 \\
\hline Continuous & 11 & 17 & 12 & 38 & 2.05 & 0.76 to 5.55 & 0.16 \\
\hline \multicolumn{8}{|l|}{ Antimuscarinic MDI } \\
\hline Atrovent & 4 & 24 & 4 & 46 & 1.92 & 0.44 to 8.27 & 0.38 \\
\hline Oxivent & 2 & 26 & 2 & 48 & 1.85 & 0.25 to 13.69 & 0.55 \\
\hline Atrovent nebuliser & 9 & 19 & 7 & 43 & 2.91 & 0.96 to 8.80 & 0.06 \\
\hline Methotrexate & 1 & 27 & 2 & 48 & 0.89 & 0.08 to 10.41 & 0.93 \\
\hline Psychotropics & 5 & 23 & 2 & 48 & 5.22 & 1.07 to 25.50 & 0.04 \\
\hline
\end{tabular}



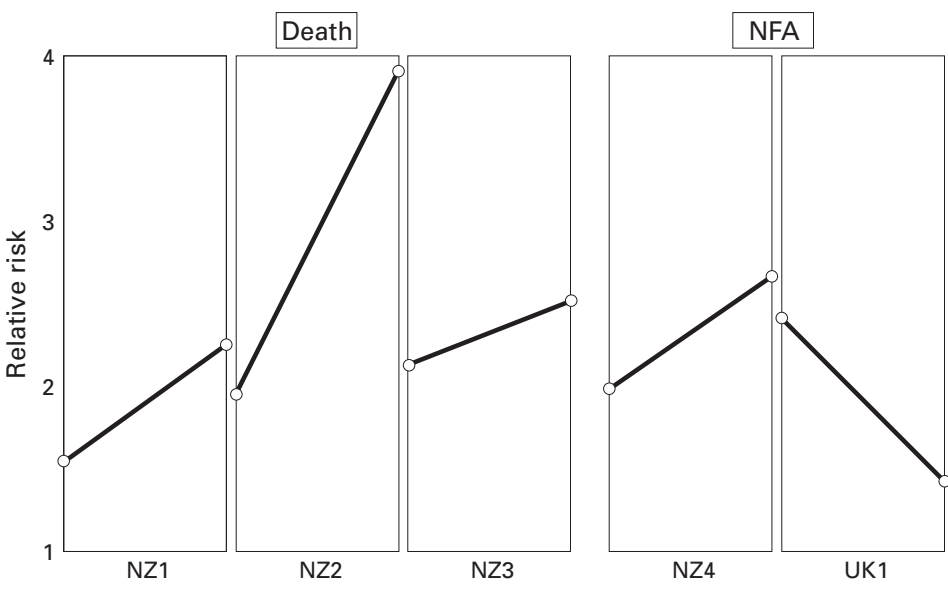

Fenoterol

Figure 1 Comparison of salmeterol findings with those relating to fenoterol from the similar New Zealand case-control studies of near-fatal asthma (NFA; NZ4) ${ }^{27}$ and deaths from asthma $\left(N Z 1,{ }^{20} N Z 2,{ }^{28}\right.$ and $\left.N Z 3^{29}\right)$. For each study the left hand axis shows the overall relative risk of death or NFA for those prescribed fenoterol/salmeterol; the right hand axis represents the same analysis in the subgroup of those patients with a hospital admission in the previous 12 months (the most valid marker of chronic asthma severity). These contrasting patterns indicate that the increased risk of death or NFA associated with fenoterol was not due to confounding by severity but was, in fact, more marked in the most severe patients; by contrast, the relative risk for salmeterol decreased when the analysis was restricted to more severe asthmatics indicating that the increased risk of NFA associated with salmeterol was largely due to confounding by severity.

other forms of drug therapy was due to confounding by severity, additional analyses were undertaken, the most important being determination of the direction and degree of the modification of the relative risk when analysis was restricted to the subgroups with the most severe chronic asthma. ${ }^{25}$ For salmeterol the relative risk decreased from 2.32 to 1.42 in the severe subgroup defined by patients with a recent hospital admission, indicating that the unadjusted findings were probably largely due to confounding by severity - that is, the increased relative risk was due to patients with more severe asthma (at greatest risk of a nearfatal attack) being preferentially prescribed salmeterol. However, this interpretation must be treated with some caution since there was a lesser decline when other markers of chronic asthma severity were used and because this stratified analysis was based on small numbers of cases and controls.

Nevertheless, this interpretation is supported by the analysis which demonstrated that a greater proportion of patients within the subgroups with more severe chronic asthma were prescribed salmeterol. For example, amongst patients admitted to hospital with asthma, those with the most severe asthma (defined by either a recent hospital admission, requirement for continuous oral steroids, or three or more categories of asthma drugs) were prescribed salmeterol two to three times as often as those with less severe asthma.

It is interesting to contrast these findings with the similar case-control studies investigating the role of the $\beta$ agonist fenoterol in the epidemic of asthma deaths in New Zealand. In all four New Zealand case-control

studies which employed similar methodology ${ }^{2027-29}$ the risk of death from asthma or a near-fatal attack associated with fenoterol increased when the analysis was restricted to the subgroups with greater chronic asthma severity (fig 1). For example, in the previous study of near-fatal attacks the relative risk associated with fenoterol increased from 2.0 to 2.6 in the severe subgroup defined by patients with a recent hospital admission. These contrasting results indicate that the increased risk of death or near-fatal asthma attack associated with fenoterol was not due to confounding by severity, but was more marked in the most severe asthmatic patients. This interpretation was consistent with other evidence that fenoterol was not preferentially prescribed to asthmatic patients with more severe asthma. ${ }^{25}$

The administration of the $\beta$ agonists salbutamol and terbutaline by nebuliser (but not metered dose inhaler) was associated with an increased risk of a near-fatal attack, with the risk increasing further in the severity subgroup analysis. Consistent with the previous study of near-fatal attacks, ${ }^{27}$ prescribed oral theophylline was associated with an increased risk, with only a modest reduction when the findings were stratified on markers of chronic asthma severity. In contrast, the oral theophylline findings from the previous studies of fatal asthma have generally not shown an increased risk. ${ }^{202-30}$ Thus, the findings for both oral theophylline and $\beta$ agonists by nebulisation have been inconsistent across the various casecontrol studies and will require further investigation, particularly with respect to the way in which these drugs are used in the long term treatment and emergency management of asthma.

The other feature of this present study was the trend towards a reduced risk of a near-fatal attack in association with inhaled corticosteroid use in the severity subgroup analysis. This pattern was also observed in the later analyses from the Saskatchewan study ${ }^{31}$ and is consistent with the expected protective effect of inhaled corticosteroids in long term asthma management. This study also provides further evidence that the presence of psychosocial problems is associated with an increased risk of hospital admissions for asthma, ${ }^{21}$ near-fatal attacks, ${ }^{32}$ and asthma deaths. ${ }^{2933}$

Finally, it is necessary to consider the findings of this case-control study together with controlled clinical studies which have investigated the long term safety and efficacy of salmeterol. As discussed previously, the Serevent Nationwide Surveillance Project identified that salmeterol did not increase the risk of severe attacks of asthma leading to either hospital admission or withdrawal from the study. Similarly, in more detailed controlled clinical trials involving smaller numbers of patients, the regular use of salmeterol did not increase (or protect) against severe exacerbations of asthma when compared with salbutamol. ${ }^{6-10}$ As a result, the clinical and epidemiological studies to date suggest that the long term use of salmeterol is not associated with deteriorating asthma control, leading to severe attacks requiring ad- 
mission to hospital or an intensive care unit. Conversely, despite marked symptomatic and lung function improvement, the regular use of salmeterol does not appear to protect against the frequency or magnitude of severe attacks of asthma.

In summary, the findings of this study provide little support for the hypothesis that the use of salmeterol by patients with chronic severe asthma increases the risk of a near-fatal attack. If a near-fatal attack is considered to be an intermediate step in a process by which a severe attack of asthma may become fatal, these results would suggest that salmeterol is unlikely to be associated with a significantly increased risk of death, at least by this mechanism. However, due to the difficulties associated with the use of a near-fatal attack as a marker of the risk of a fatal attack of asthma, ${ }^{18}$ and the findings of the Serevent Nationwide Surveillance Study in relation to mortality, ${ }^{13}$ it is still necessary to investigate formally through case-control studies of asthma mortality whether salmeterol increases the risk of death from asthma.

We gratefully acknowledge the expert secretarial assistance from Denise Fabian and financial support from the Hartley Trust, University of Southampton and from the University of Otago.
The Wellington Asthma Research Group is funded by a ProThe Wellington Asthma Research Group is funded by a Programme Grant and Julian Crane and Neil Pearce are funded New Zealand.

1 Pearce N, Beasley R, Crane J, Burgess C. Epidemiology of asthma mortality. In: Holgate S, Busse W, eds. Asthma and rhinitis. Oxford: Blackwell Scientific Press, 1994: 58-69.

2 Beasley R, Pearce N, Crane J, Windom H, Burgess C. Asthma mortality and inhaled beta agonist therapy. Aust NZ F Med 1991;21:753-63.

3 Taylor DR, Sears MR. Regular beta-adrenergic agonists: evidence, not reassurance is what is needed. Chest 1994; 106:552-9

4 Barnes PJ, Lee TH, Holgate S. Asthma therapy present anxieties and future research adverse. Drug Reaction Bulletin 1992;154:579-82

5 Ullman A, Hedner J, Svedmyr N. Salmeterol, a new long acting inhaled $\beta$-adrenoceptor agonist: comparison with salbutamol in adult asthmatic patients. Thorax 1988;43: 674-8.

6 Pearlman DS, Chervinsky P, LaForce C, et al. A comparison of salmeterol with albuterol in the treatment of mild-toof salmeterol with albuterol in the treatment of mild
moderate asthma. $N$ Engl f Med 1992;327:1420-5.

moderate asthma. N Engl f Med 1992;327:1420-5.
7 D'Alonzo GE, Nathan RA, Henochowicz S, Morris RJ, Ratner P, Rennard SI. Salmeterol xinafoate as mainRatner P, Rennard SI. Salmeterol xinafoate as main-
tenance therapy compared with albuterol in patients with tenance therapy compared with alb
asthma. $7 A M A 1994 ; 271: 1412-6$.

8 Britton MG, Earnshaw JS, Palmer JBD. A twelve month comparison of salmeterol with salbutamol in asthmatic patients. Eur Respir ₹ 1992;5:1062-7.

9 Cheung D, Timmers MC, Zwinderman AH, Bei EH, Dijkman JH, Sterk PJ. Long-term effects of a long-acting $\beta_{2}$-adrenoceptor agonist, salmeterol, on airway hyperresponsiveness in patients with mild asthma. $N$ Engl $f$ Med 1992;327:1198-203.

10 Ullman A, Hedner J, Svedmyr N. Inhaled salmeterol and salbutamol in asthmatic patients: an evaluation of asthma symptoms and the possible development of tachyphylaxis. Am Rev Respir Dis 1990;142:571-5.

11 Grove A, Lipworth BJ. Bronchodilator subsensitivity to salbutamol after twice daily salmeterol in asthmatic patients. Lancet 1995;346:201-6.

12 Ramage L, Lipworth BJ, Ingram CG, Cree A, Dhillon DP. Reduced protection against exercise induced bronchoconstriction after chronic dosing with salmeterol. $R e$ spir Med 1994;88:363-8.

13 Castle W, Fuller R, Hall J, Palmer J. Serevent nationwide surveillance study: comparison of salmeterol with salbutamol in asthmatic patients who require regular bronchodilator treatment. BMF 1993;306:1034-7.

14 Mann RD, Kubota K, Pearce G, Wilton L. Salmeterol: a study by prescription-event monitoring in a UK cohort of 15,407 patients. F Clin Epidemiol 1996;49:247-50.

15 Finkelstein FN. Risks of salmeterol. N Engl f Med 1994, 331:1314.

16 Palmer JBD, Rickard KA, Thompson JR. Risks of salmeterol. N Engl f Med 1994;331:1314

17 Beasley R, Pearce NE, eds. The role of beta agonist therapy in asthma mortality. New York: CRC Press, 1993

18 Beasley R, Pearce N, Crane J. Use of near-fatal asthma fo investigating asthma deaths. Thorax 1993;48:1093-4.

19 Sears MR, Rea HH, de Boer G, et al. Accuracy of certification of deaths due to asthma: a national study. $A m^{f}$ Epidemiol 1986;124:1004-11.

20 Crane J, Pearce N, Flatt A, et al. Prescribed fenoterol and death from asthma in New Zealand, 1981-83: a case control study. Lancet 1989; i:917-22.

21 Rea HH, Scragg R, Jackson R, Beaglehole R, Fenwick J, Sutherland DC. A case-control study of deaths from asthma. Thorax 1986;41:833-9.

22 Crane J, Pearce NE, Burgess C, Woodman K, Robson B, Beasley R. Markers of risk of asthma death or readmission in the 12 months following a hospital admission for asthma. Int 7 Epidemiol 1992;21:737-44.

23 Mantel N, Haenszel W. Statistical aspects of the analysis of data from retrospective studies of disease. 7 Natl Cancer data from retrospective

24 Miettinen OS. Estimability and estimation in case-referent studies. Am f Epidemiol 1976;103:226-35.

25 Beasley R, Burgess C, Pearce N, Grainger J, Crane J. Confounding by severity does not explain the association between fenoterol and asthma death. Clin Exp Allergy 1994;24:660-8.

26 Hill NS, Weiss EB. Status asthmaticus. In: Weiss EB, Stein $\mathrm{M}$, eds. Bronchial asthma: mechanisms and therapeutics. 3rd edn. Boston: Little, Brown, 1993: 985-1016.

27 Burgess C, Pearce N, Thiruchelvam R, et al. Prescribed drug therapy and near-fatal asthma attacks. Eur Respir $f$ 1994;7:498-503.

28 Pearce N, Grainger J, Atkinson M, et al. Fenoterol and death from asthma in New Zealand 1977-1981. Thorax 1990;45:170-5.

29 Grainger J, Woodman K, Pearce N, et al. Prescribed fenoterol and death from asthma in New Zealand, 19811987: a further case-control. Thorax 1991;46:105-11.

30 Spitzer WO, Suissa S, Ernst P, et al. The use of beta agonists and the risk of death and near death from asthma. N Engl 7 Med 1992;326:501-6.

31 Suissa S, Ernst P, Boivin J-F, et al. A cohort analysis of excess mortality in asthma and the use of inhaled $\beta$ agonists. Am $\mathcal{F}$ Respir Crit Care Med 1994;149:604-10.

32 Yellowlees PM, Ruffin RE. Psychosocial defences and coping styles in patients following a life-threatening attack of asthma. Chest 1989;95:1298-303.

33 Wareham NJ, Harrison BDW, Jenkins PF, Nicholls J, Stableforth DE. A district confidential enquiry into deaths due to asthma. Thorax 1993;48:1117-20. 